\title{
Simple organic molecules bearing a 3,4-ethylenedioxythiophene linker for efficient dye-sensitized solar cells $\dagger$
}

\author{
Wei-Hsin Liu, ${ }^{a} \mathrm{I}-\mathrm{Che} \mathrm{Wu},{ }^{a}$ Chin-Hung Lai, ${ }^{a}$ Cheng-Hsuan Lai, ${ }^{a}$ Pi-Tai Chou,,$* a$ \\ Yi-Tsung Li, ${ }^{b}$ Chao-Ling Chen, ${ }^{b}$ Yu-Yen $\mathrm{Hsu}^{b}$ and Yun Chi ${ }^{b}$
}

Received (in Cambridge, UK) 20th May 2008, Accepted 29th August 2008

First published as an Advance Article on the web 24th September 2008

DOI: $10.1039 / b 808535 h$

\begin{abstract}
3,4-Ethylenedioxythiophene and bis[2-(2-methoxyethoxy)ethoxy]thiophene bridged donor-acceptor molecules for dye-sensitized solar cells have been synthesized, one of which achieved a solarto-energy conversion efficiency of $7.3 \%$, compared to $7.7 \%$ optimized for N719 dye.
\end{abstract}

Owing to their versatility and low cost, ${ }^{1}$ dye-sensitized solar cells (DSSCs) have attracted much attention since the breakthrough in conversion efficiency that Grätzel and co-workers made with Ru-based photosensitizers. Accordingly, their breakthrough initiated intensive investigation, among which the most common sensitizers should be ascribed to cis-dithiocyanato bis(4,4'-dicarboxy-2,2'-bipyridine) ruthenium(II) and trithiocyanato- $4,4^{\prime}, 4^{\prime \prime}$-tricarboxy-2, $2^{\prime}: 6^{\prime}, 2^{\prime \prime}$-terpyridine ruthenium(II), known as $\mathrm{N} 3$ and black dye, ${ }^{2,3}$ respectively. A new series of these dyes are widely used and show efficiencies of up to $10 \%$ under simulated AM 1.5 irradiation $\left(100 \mathrm{~mW} \mathrm{~cm}^{-2}\right){ }^{4}$ However, the high cost of $\mathrm{Ru}$ metal may hamper further developments. Alternatively, numerous organic DSSC dyes have been developed. ${ }^{5}$ Their practical advantages include: (1) larger molar extinction coefficients resulting from the allowed $\pi \pi^{*}$ transitions, (2) simple synthesis as well as facile structural modification, and (3) much less concern regarding their availability. ${ }^{6}$

Herein, we report the design and syntheses of a series of simple organic dyes (Scheme 1) that contain common triphenylamine (TPA) as donor and cyanoacrylic acid or rhodanine3 -acetic acid as electron acceptor (anchoring groups). These two moieties are bridged by thiophene and its derivatives, such as 3,4-ethylenedioxythiophene (EDOT) or 3,4-bis[2-(2-methoxyethoxy)ethoxy]thiophene (BMEET), to form organic dyes, namely: $\mathrm{L} 1,{ }^{7} \mathrm{LJ} 1-\mathrm{LJ} 3$, and $\mathrm{LJ} 4$. In contrast to many recent approaches aimed at increasing the conjugation to extend the absorption cross section and/or conducting the bathochromic shift, ${ }^{8}$ we attempted instead to simplify the D-A structure such that planarity can be reached easily and hence the efficiency of charge transfer can be enhanced to compensate for its possible inferiority of a relatively large energy gap. Especially, the introduction of EDOT has its own niche in that

\footnotetext{
${ }^{a}$ Department of Chemistry, National Taiwan University, Taipei 10617, Taiwan.E-mail: chop@ntu.edu.tw

${ }^{b}$ Department of Chemistry, National Tsing Hua University, Hsinchu 30013,Taiwan.E-mail: ychi@mx.nthu.edu.tw

$\dagger$ Electronic supplementary information (ESI) available: Syntheses, characterization, devices and measurements. See DOI: 10.1039/ b808535h
}

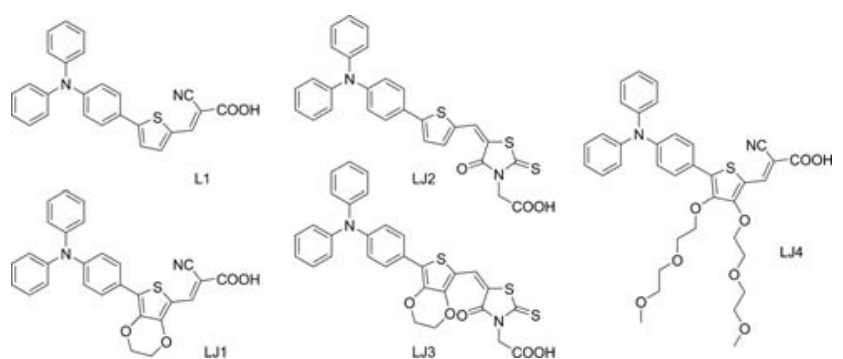

Scheme 1 Schematic structure of TPA dyes mentioned in this article.

poly-3,4-ethylenedioxythiophene (PEDOT) has been applied in the fabrication of polymer based photovoltaics. ${ }^{9}$ Thus, if successful, the high product yield, low cost, and versatility of chemical modification may provide greatly superior DSSCs.

The synthetic protocols leading to the isolation of L1 and LJ1-LJ4 are depicted in the ESI. $\dagger$ They consist of treatment of TPA substituted boronic acid with 5-formyl-2-bromothiophene or the corresponding EDOT derivative under conditions for Suzuki coupling, followed by condensation with cyanoacrylic acid or rhodanine-3-acetic acid in the presence of ammonium acetate. ${ }^{10}$ Note that L1, which serves as a control unit for other dyes, has already been documented, including its performance properties. $^{7}$

Fig. 1 shows the UV-Vis spectra for L1 and LJ1-LJ4 in tert-butanol-acetonitrile (1:1) solutions. The strong absorption band can apparently be attributed to the intramolecular charge transfer between the TPA donor to cyanoacrylic acid or rhodanine-3-acetic acid. LJ2 and LJ3 dyes bearing rhodanine-3-acetic acid as the acceptor show a significant red shift in

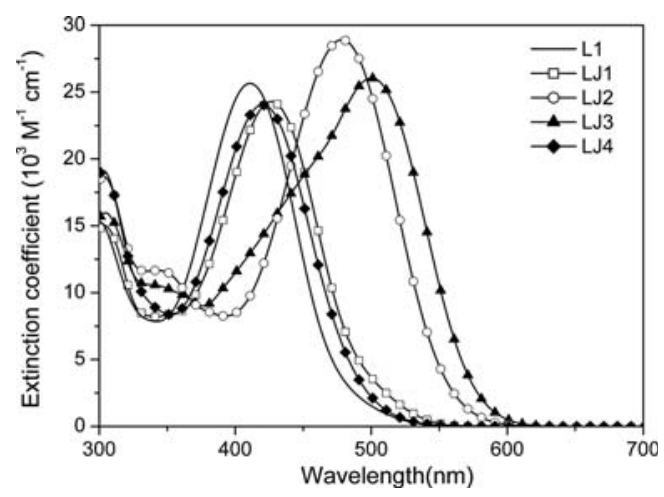

Fig. 1 Absorption spectra of TPA derivatives in tert-butanolacetonitrile $(1: 1)$ solution. 
Table 1 Photophysical, electrochemical and photovoltaic performance data of organic dyes

\begin{tabular}{|c|c|c|c|c|c|c|c|c|c|}
\hline \multirow[b]{2}{*}{ Dye } & \multirow{2}{*}{$\begin{array}{l}\text { Absorption } \\
\lambda_{\text {abs }}{ }^{a} / \mathrm{nm}\left(\varepsilon / \mathrm{M}^{-1} \mathrm{~cm}^{-1}\right)\end{array}$} & \multirow{2}{*}{$\begin{array}{l}\text { Emission } \\
\lambda_{\mathrm{em}}{ }^{a} / \mathrm{nm}\end{array}$} & \multicolumn{3}{|c|}{$\underline{\text { Potentials and energy levels }}$} & \multicolumn{4}{|c|}{$\underline{\text { Photovoltaic performance data }}{ }^{d}$} \\
\hline & & & $E_{\mathrm{ox}}^{b} / \mathrm{V}$ & $E_{0-0}{ }^{c} / \mathrm{V}$ & $E_{\mathrm{ox}}-E_{0-0} / \mathrm{V}$ & $J_{\mathrm{sc}} / \mathrm{mA} \mathrm{cm}^{-2}$ & $V_{\mathrm{oc}} / \mathrm{mV}$ & FF & $\eta(\%)$ \\
\hline L1 & $410(25800)$ & 549 & 1.06 & 2.40 & -1.34 & 12.8 & 620 & 0.66 & 5.20 \\
\hline LJ1 & $426(24500)$ & 548 & 0.98 & 2.53 & -1.55 & 15.5 & 690 & 0.683 & 7.30 \\
\hline $\mathrm{LJ} 2$ & $477(29000)$ & 624 & 1.00 & 2.24 & -1.24 & 7.8 & 570 & 0.684 & 3.04 \\
\hline LJ3 & $501(26100)$ & 625 & 0.93 & 2.17 & -1.24 & 8.0 & 580 & 0.685 & 3.18 \\
\hline LJ4 & $420(24000)$ & 548 & 1.05 & 2.53 & -1.48 & 10.7 & 750 & 0.668 & 5.36 \\
\hline
\end{tabular}

${ }^{a}$ Absorption and emission spectra were measured in tert-butanol-acetonitrile $(1: 1)$ solution. ${ }^{b}$ The oxidation potentials of dyes on $\mathrm{TiO}_{2}$ were measured in $\mathrm{CH}_{3} \mathrm{CN}$ with $0.1 \mathrm{M}$ tetrabutylammonium hexafluorophosphate (TBAP) with a scan rate of $50 \mathrm{mV} \mathrm{s}{ }^{-1}$ (vs. NHE). ${ }^{c} E_{0}-0$ was determined from the intersection of absorption and emission spectra. ${ }^{d}$ The concentration was maintained at $3 \times 10^{-4} \mathrm{M}$ in tert-butanolacetonitrile $(1: 1)$ solution, with $1 \mathrm{mM}$ deoxycholic acid (DCA) as a coadsorbate, and 0.6 M 1-butyl-3-methylimidazolium iodide (BMII), $0.1 \mathrm{M} \mathrm{LiI,}$ $0.05 \mathrm{M} \mathrm{I}_{2}, 0.5 \mathrm{M}$ 4-tert-butylpyridine (TBP) in dry acetonitrile as electrolyte. Performances of DSSCs were measured with a $0.25 \mathrm{~cm}^{2}$ working area.

the $\mathrm{S}_{0}-\mathrm{S}_{1}$ absorption band compared with that of the $\mathrm{L} 1$ and LJ1 dyes. Moreover, the LJ4 dye with BMEET, and the LJ1 and LJ3 dyes with the EDOT linker, also show a bathochromic shift compared with $\mathrm{L} 1$ and LJ2, respectively. This red-shift may favor light harvesting and hence photocurrent generation in DSSCs (vide infra).

The $E_{\text {ox }}$ of the dyes adsorbed on a $6 \mu \mathrm{m}$ thick $\mathrm{TiO}_{2}$ nanocrystalline film on transparent conducting oxide (TCO) glass were measured using cyclic voltammetry (see Table 1). The results reveal that the redox potential of $\mathrm{I} / \mathrm{I}_{3}{ }^{-}$(ca. $0.4 \mathrm{~V} v$. NHE) is more negative than the HOMO and is able to regenerate the dyes from electron donation. The LUMO levels of these dyes are also sufficiently more negative than the conduction band edge of the $\mathrm{TiO}_{2}$ electrode $(-0.5 \mathrm{~V} v s$. NHE at $\mathrm{pH} 7) .{ }^{11}$ The large energy gap, calculated from the LUMO of the dye and the $E_{\mathrm{cb}}$ of the $\mathrm{TiO}_{2}$ electrode, provides a favorable energy to inject electrons into the $\mathrm{TiO}_{2}$ electrode, while incorporation of 4-tert-butylpyridine also decreased the dark current and improved device efficiency. ${ }^{12}$ As a result, the open-circuit voltage and fill factor are improved, leading to an increase in overall conversion efficiencies.

All essential properties of these DSSC dyes are listed in Table 1, and the respective $J-V$ curves are shown in Fig. 2. Under the standard AM $1.5 \mathrm{G}$ irradiation, the maximum efficiency $(\eta)$ for the LJ1-sensitized solar cell with an active cell area of $0.25 \mathrm{~cm}^{2}$ was calculated to be $7.3 \%$, with a shortcircuit current $\left(J_{\mathrm{sc}}\right)$ of $15.5 \mathrm{~mA} \mathrm{~cm} \mathrm{~cm}^{-2}$ and an open-circuit voltage $\left(V_{\text {oc }}\right)$ of $690 \mathrm{mV}$, while the DSSCs based on L1 showed

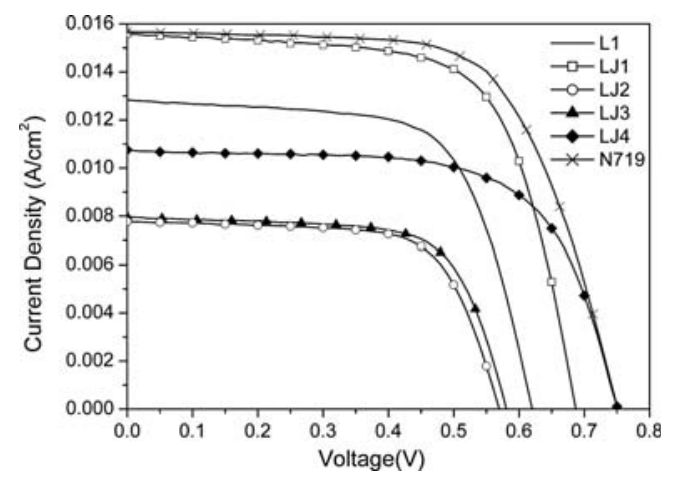

Fig. 2 Photocurrent density vs. voltage curves for DSSCs based on L1, LJ1-LJ4 and N719 under AM 1.5 G simulated solar light $\left(100 \mathrm{~mW} \mathrm{~cm}^{-2}\right)$. relatively lower $J_{\mathrm{sc}}$ and $V_{\mathrm{oc}}$, leading to a lower $\eta$ value of $5.2 \%$. The device based on $\mathrm{L} 1$ with a thinner $\mathrm{TiO}_{2}$ film showed a lowered $\eta$ value of $2.75 \%{ }^{7}$ Moreover, the related TPA dye without the bridging thiophene showed an even lower $\eta$ value of $2.47 \%{ }^{13}$ In another approach, DSSCs based on LJ 2 and LJ3 showed greatly inferior efficiencies of $3.04 \%$ and $3.18 \%$, respectively, even though they had much broader spectral response and higher extinction coefficients. For a fair comparison, the N719-sensitized $\mathrm{TiO}_{2}$ solar cell showed an efficiency of $7.7 \%$, with a $J_{\mathrm{sc}}$ of $15.6 \mathrm{~mA} \mathrm{~cm} \mathrm{~cm}^{-2}$, a $V_{\text {oc }}$ of $750 \mathrm{mV}$, and a fill factor (FF) of 0.66 .

The incident photon-to-current conversion efficiencies (IPCEs) of these DSSC dyes are shown in Fig 3. The onset of the IPCE spectrum based on LJ1 is $\sim 660 \mathrm{~nm}$, and high IPCE performance ( $>80 \%$ ) was observed from 400 to $570 \mathrm{~nm}$, with the highest value, $92 \%$, at $450 \mathrm{~nm}$. In contrast, despite the onset of the IPCE spectra of DSSCs of $\sim 750 \mathrm{~nm}$ for both LJ2 and LJ3, they exhibited lower IPCEs with maxima of $40 \%$ at $\sim 500 \mathrm{~nm}$. The rather low IPCE values for LJ2 and LJ3 dyes reflect lower photocurrent and hence inferior photovoltaic performance. The results may indicate that rhodanine-3-acetic acid is a poor anchor in comparison to cyanoacrylic acid. ${ }^{14}$

We then estimated the amounts of dye adsorbed on the $\mathrm{TiO}_{2}$ films by desorbing the dye with basic solution. The concentrations were then determined to be $1.8 \times 10^{-7}, 1.7 \times 10^{-7}$ and $1.4 \times 10^{-7} \mathrm{M} \mathrm{cm}^{-2}$ for $\mathrm{L} 1, \mathrm{LJ} 1$ and $\mathrm{LJ} 4$, respectively. The side chain of LJ4 leads to less dye-uptake. It is thus reasonable to conclude that broader spectral response, higher molar

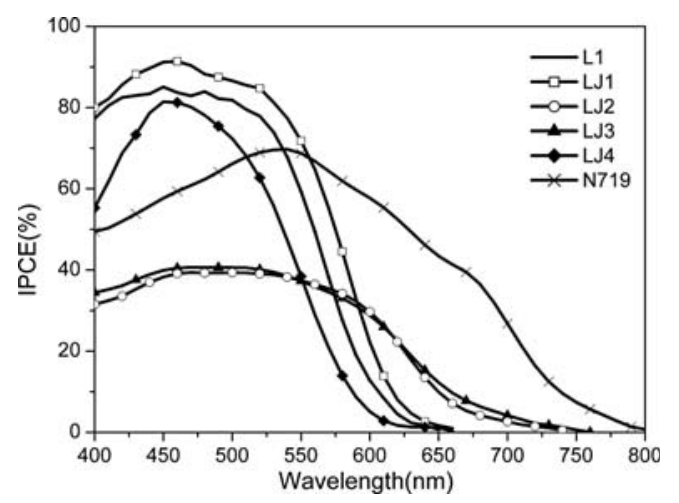

Fig. 3 The incident photon-to-current conversion efficiencies spectra for DSSCs based on L1, LJ1-LJ4 and N719. 


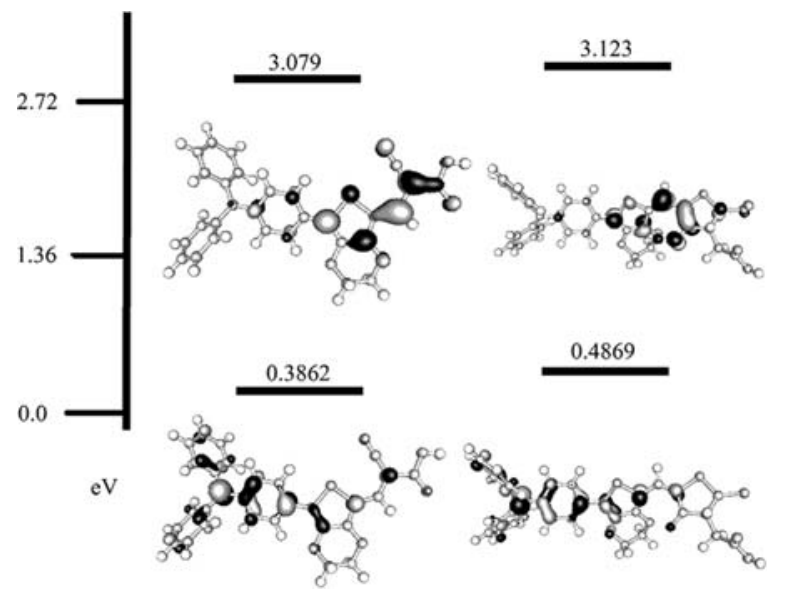

Fig. 4 The calculated frontier orbitals of LJ1 (left) and LJ3 (right).

absorption coefficient and higher amounts of dye adsorbed on the $\mathrm{TiO}_{2}$ films account for the higher conversion efficiency for LJ1. To gain more insight, theoretical analysis (density functional theory (DFT), B3LYP/6-31G(d) level) on the molecular orbitals involved in the transitions was carried out, and the resulting frontier orbitals are depicted in Fig. 4. Clearly, the lowest transition was dominated by charge transfer from the TPA to the cyanoacrylic acid or rhodanine-3-acetic acid moiety. It is noteworthy that the LUMO electron density of L1 and LJ1 is located mainly on the cyanoacrylic acid, such that the excited electron can be injected into the $\mathrm{TiO}_{2}$ electrode effectively. However, LJ2 and LJ3 each have a methylene group that disrupts the $\pi^{*}$ conjugation between rhodanine and the carboxylic acid, hence decreasing the electron injection efficiency in a dynamic manner. The electrochemical impedance experiments showed the electron lifetime being shortened in device LJ3 more than in LJ1 (see Fig. S3 in ESI $\dagger$ ). This explains the superiority of L1 and LJ1 over LJ2 and LJ3, respectively.

In yet another approach, we synthesized the LJ4 dye with the BMEET linker. The resulting $J-V$ and IPCE plots are also included in Fig. 2 and 3. In comparison to that of $\mathrm{LJ} 1$, the slightly lower $\eta$ value of 5.36 directly reflects its lower spectral response. However, the higher $V_{\text {oc }}$ value of $750 \mathrm{mV}$ was obtained due to the suppression of dark current from the free $\mathrm{TiO}_{2}$ conduction-band to the counter electrolyte. ${ }^{15}$ Further suppression has been achieved via replacement of lithium iodide by cuprous iodide, as supported by the resulting $V_{\mathrm{oc}}$ of $800 \mathrm{mV}$. Unfortunately, the conversion efficiency was not accordingly gained, due to a lower $J_{\mathrm{sc}}{ }^{16}$

In summary, simple donor-acceptor designs bearing EDOT or BMEET linkers were synthesized with high yields. The introduction of the EDOT group in LJ1 increases the spectral response and perhaps renders a better degree of charge separation, resulting in a leap in the photovoltaic performance in comparison to its parent compound L1, and exhibits a conversion efficiency $\eta$ as high as $7.3 \%$. The lower IPCEs obtained for the LJ2 and LJ3 dyes could be the result of the LUMO being located in a rhodanine framework rather than at the carboxylic acid group; the result effectively reduces the electron injection efficiency. Our results strongly support the successful prospects of simple organic DSSC photosensitizers such as LJ1 and its future derived analogues.

\section{Notes and references}

1 M. K. Nazeeruddin and M. Grätzel, in Molecular and Supramolecular Photochemistry, ed. V. Ramamurthy and K. Schanze, Marcel-Dekker, New York, NY, 2002, vol. 10, pp. 301-343.

2 M. K. Nazeeruddin, A. Kay, I. Rodicio, R. H. Baker, E. Muller, P. Liska, N. Vlachopoulos and M. Grätzel, J. Am. Chem. Soc., 1993, 115, 6382 .

3 M. K. Nazeeruddin, P. Péchy, T. Renouard, S. M. Zakeeruddin, R. H. Baker, P. Comte, P. Liska, L. Cevey, E. Costa, V. Shklover, L. Spiccia, G. B. Deacon, C. A. Bignozzi and M. Grätzel, J. Am. Chem. Soc., 2001, 123, 1613.

4 (a) F. Gao, Y. Wang, J. Zhang, D. Shi, M. Wang, R. H. Baker, P. Wang, S. M. Zakeeruddin and M. Grätzel, Chem. Commun., 2008, 2635; (b) F. Gao, Y. Wang, D. Shi, J. Zhang, M. Wang, X. Jing, R. Humphry-Baker, P. Wang, S. M. Zakeeruddin and M. Grätzel, J. Am. Chem. Soc., 2008, 130, 10720.

5 (a) K. Hara, K. Sayama, Y. Ohga, A. Shinpo, S. Suga and H. Arakawa, Chem. Commun., 2001, 569; (b) T. Horiuchi, H. Miura and S. Uchida, Chem. Commun., 2003, 3036; (c) Y. S. Chen, C. Li, Z. H. Zeng, W. B. Wang, X. S. Wang and B. W. Zhang, J. Mater. Chem., 2005, 15, 1654; (d) K. Hara, Z.-S. Wang, T. Sato, A. Furube, R. Katoh, H. Sugihara, Y. Dan-oh, C. Kasada, A. Shinpo and S. Suga, J. Phys. Chem. B, 2005, 109, 15476; (e) D. P. Hagberg, T. Edvinsson, T. Marinado, G. Boschloo, A. Hagfeldt and L. Sun, Chem. Commun., 2006, 2245; (f) Z. S. Wang, Y. Cui, K. Hara, Y. Dan-oh, C. Kasada and A. Shinpo, Adv. Mater., 2007, 19, 1138; (g) S. Hwang, J. H. Lee, C. Park, H. Lee, C. Kim, C. Park, M.-H. Lee, W. Lee, J. Park, K. Kim, N.-G. Park and C. Kim, Chem. Commun., 2007, 4887; (h) I. Jung, J. K. Lee, K. H. Song, K. Song, S. O. Kang and J. Ko, J. Org. Chem., 2007, 72, 3652; (i) P. Qin, X. Yang, R. Chen, L. Sun, T. Marinado, T. Edvinsson, G. Boschloo and A. Hagfeldt, J. Phys. Chem. C, 2007, 111, 1853; (j) M.-S. Tsai, Y.-C. Hsu, J. T. Lin, H.-C. Chen and C.-P. Hsu, J. Phys. Chem. C, 2007, 111, 18785; (k) W. H. Howie, F. Claeyssens, H. Miura and L. M. Peter, J. Am. Chem. Soc., 2008, 130, 1367; (l) D. Kuang, S. Uchida, R. Humphry-Baker, S. M. Zakeeruddin and M. Grätzel, Angew. Chem., Int. Ed., 2008, 47, 1923.

6 Z. Chen, F. Li and C. Huang, Curr. Org. Chem., 2007, 11, 1241.

7 D. P. Hagberg, T. Marinado, K. M. Karlsson, K. Nonomura, P. Qin, G. Boschloo, T. Brinck, A. Hagfeldt and L. Sun, J. Org. Chem., 2007, 72, 9550 .

8 (a) K. R. J. Thomas, J. T. Lin, Y.-C. Hsu and K.-C. Ho, Chem. Commun., 2005, 4098; (b) S.-L. Li, K.-J. Jiang, K.-F. Shao and L.-M. Yang, Chem. Commun., 2006, 2792; (c) R. Chen, X. Yang, H. Tian, X. Wang, A. Hagfeldt and L. Sun, Chem. Mater., 2007, 19, 4007; (d) Z. Ning, Q. Zhang, W. Wu, H. Pei, B. Liu and H. Tian, J. Org. Chem., 2008, 73, 3791.

9 (a) H. Choi, J. K. Lee, K. H. Song, K. Song, S. O. Kang and J. Ko, Tetrahedron, 2007, 63, 1553; (b) Q. Peng, K. Park, T. Lin, M. Durstock and L. Dai, J. Phys. Chem. B, 2008, 112, 2801; (c) J. Xia, N. Masaki, M. Lira-Cantu, Y. Kim, K. Jiang and S. Yanagida, J. Am. Chem. Soc., 2008, 130, 1258.

10 (a) M. Velusamy, K. R. J. Thomas, J. T. Lin, Y.-C. Hsu and K.-C. Ho, Org. Lett., 2005, 7, 1899; (b) K. R. J. Thomas, Y.-C. Hsu, J. T. Lin, K.-M. Lee, K.-C. Ho, C.-H. Lai, Y.-M. Cheng and P.-T. Chou, Chem. Mater., 2008, 20, 1830.

11 C. Klein, M. K. Nazeeruddin, D. D. Censo, P. Liska and M. Grätzel, Inorg. Chem., 2004, 43, 4216.

12 G. Boschloo, L. Häggman and A. Hagfeldt, J. Phys. Chem. B, 2006, 110, 13144.

13 W. Xu, B. Peng, J. Chen, M. Liang and F. Cai, J. Phys. Chem. C, $2008,112,874$.

14 (a) H. Tian, X. Yang, R. Chen, Y. Pan, L. Li, A. Hagfeldt and L. Sun, Chem. Commun., 2007, 3741; (b) M. Liang, W. Xu, F. Cai, P. Chen, B. Peng, J. Chen and Z. Li, J. Phys. Chem. C, 2007, 111, 4465 .

15 N. Koumura, Z.-S. Wang, S. Mori, M. Miyashita, E. Suzuki and K. Hara, J. Am. Chem. Soc., 2006, 128, 14256.

16 D. Kuang, C. Klein, S. Ito, J. Moser, R. H. Baker, S. M. Zakeeruddin and M. Grätzel, Adv. Funct. Mater., 2007, 17, 154. 